\title{
An In Situ Method of Creating Metal Oxide-Carbon Composites and Their Application as Anode Material for Lithium-Ion Batteries
}

Zichao Yang, Jingguo Shen, and Lynden A. Archer ${ }^{*}$

Transition metal oxides are actively investigated as anode materials for lithium-ion batteries (LIBs), and their nanocomposites with carbon frequently show better performance in galvanostatic cycling studies, compared to the pristine metal oxide. An in-situ, scalable method for creating transition metal oxide-carbon nanocomposites has been developed based on free-radical polymerization and cross-linking of poly(acrylonitrile) in the presence of the metal oxide precursor containing vinyl groups. The approach yields a cross-linked polymer network, which uniformly incorporates nanometer-sized transition metal oxide particles. Thermal treatment of the organic-inorganic hybrid material produces nearly monodisperse metal oxide nanoparticles uniformly embedded in a porous carbon matrix. Cyclic voltammetry and galvanostatic cycling electrochemical measurements in a lithium half-cell are used to evaluate the electrochemical properties of a $\mathrm{Fe}_{3} \mathrm{O}_{4}$-carbon composite created using this approach. These measurements reveal that when used as the anode in a lithium battery, the material exhibits stable cycling performance at both low and high current densities. We further show that the polymer/nanoparticle copolymerization approach can be readily adapted to synthesize metal oxide/carbon nanocomposites based on different particle chemistries for applications in LIBs.

School of Chemical and Biomolecular Engineering, Cornell University, Ithaca, New York14853,USA.Email: laa25@cornell.edu. 


\section{Introduction}

Lithium-ion batteries (LIBs) demonstrate higher energy density, higher operating voltage and lower self-discharge rates compared to conventional rechargeable batteries. They have consequently received intense scientific and commercial interest for portable electronics applications since the early 1990s. In recent years, the demand for secondary (rechargeable) batteries with better performance, higher charge-rate capability, improved cycling stability, and enhanced safety has steadily increased to meet new needs for smaller, lighter, more powerful electronic devices, as well as to accommodate growing interests in hybrid electric and plug-in hybrid electric vehicles.

Despite the sustained efforts of research groups worldwide, the performance achieved with the current LIB platforms based on a graphite anode and a lithium metal oxide (e.g. $\mathrm{LiCoO}_{2}$ ) cathode is believed to be close to its limits. ${ }^{1}$ The limited gravimetric capacity and rate capability of graphitic carbon as the anode material has, for example, spurred tremendous interest in research towards alternative anode materials with large capacities at low potentials. Transition-metal oxides have received much attention because of their high theoretical capacity (typically $2 \sim 3$ times that for graphitic carbon, $372 \mathrm{mAh} / \mathrm{g}$ ). However, many of these materials undergo undesirable structural changes during cyclic uptake and release of lithium, which leads to unsatisfactory cycling performance.

The mechanisms for lithium storage in transition metal oxides generally falls in two categories: insertion reaction, which refers to intercalation of lithium ions into the host material without causing fundamental structural change in the latter, or 
conversion reaction, which involves reduction of the metal oxide to pure metal with generation of $\mathrm{Li}_{2} \mathrm{O}{ }^{2}$ The majority of metal oxides exhibit conversion reactions with lithium and the large volume changes and consequent local stress concentration caused by repeated metal/ $\mathrm{Li}_{2} \mathrm{O}$ formation and regeneration has long been considered a major reason for their unsatisfactory cycling performance. ${ }^{2}$ A direct consequence of these stresses is breakdown of the active particles by means of a fatigue-like failure process, which produces cracking and degradation of the primary structures after many charge-discharge cycles. Broadly termed the pulverization problem, this breakdown is believed to simultaneously interrupt ionic and electronic conduction pathways in the electrode, and to create new surfaces that can react with the electrolyte, which continuously changes the surface electrolyte interface (SEI) and depletes the active material. An important approach to mitigate/resolve the pulverization problem is to employ nanometer-scale particles with designed morphology, such as nanospheres, nanowires, nanotubes. ${ }^{3-6}$ Hollow structures with strong, permeable shells and copious void space, to accommodate the large stresses produced by volume change, have also been shown to be advantageous in improving performance of many anode materials, including $\mathrm{Co}_{3} \mathrm{O}_{4}$ and $\mathrm{SnO}_{2} \cdot{ }^{7-9}$

Besides designing nanostructures with unique morphologies, another commonly used technique in tackling the pulverization issue is the creation of carbon composites for these metal oxides. The role of the carbon is generally believed to be two-fold: First, it improves the mechanical flexibility of the active material; and second, it provides a mechanism for maintaining electronic contiguity of the active material 
even after structural breakdown. Carbon nanopainting, namely, the introduction of a layer of carbon coating on the metal oxides nanoparticles, is an attractive approach for introducing a captive carbon shell to metal oxide nanostructures. The carbon is usually amorphous and made from sugars (e.g. glucose or sucrose) and the method is applicable to various metal oxides or related compounds, such as $\mathrm{Fe}_{3} \mathrm{O}_{4}, \mathrm{SnO}_{2}$ and lithium titanate. ${ }^{10-17}$ Another frequently used approach employs porous carbon or graphene/CNT as substrate materials for synthesis of captive nanoparticles embedded in or (probably only loosely) bonded to the carbon. An advantage of this method it that it is applicable to a variety of metal oxides such as $\mathrm{Fe}_{3} \mathrm{O}_{4}$ and $\mathrm{Co}_{3} \mathrm{O}_{4}{ }^{18,19}$ or related materials such as metallic tin. ${ }^{20}$

In addition to improving the cycle life and performance of LIB anodes, a requirement for practical implementation of particle-based, coatings-based, or substrate-based approaches for mitigating the pulverization problem is that the synthesis method for the active anode materials must be scalable. To address this challenge, many attempts have been made previously to create composites of active materials embedded in carbon matrices by blending pre-made particles with resins, sugars, graphite, activated carbon, polymer powders and polymer sol-gels ${ }^{21-25}$.

Herein we report a facile, scalable emulsion polymerization technique for synthesizing transition metal oxide nanoparticles embedded in a porous carbon matrix. The method (illustrated in Scheme 1) relies upon co-polymerization and cross-linking of the carbon precursor (acrylonitrile) and the nanoparticle precursor in a single-step; ${ }^{24}$ it yields polymer-nanoparticle hybrids with uniform particle 
distributions at high nanoparticle loadings. The procedure is also applicable for large-scale production of metal oxide-carbon composites required for commercial-scale LIB manufacturing processes. We demonstrate the procedure here using a high-capacity $(924 \mathrm{mAh} / \mathrm{g})$ transition metal oxide $\left(\mathrm{Fe}_{3} \mathrm{O}_{4}\right)$ and show that it is adaptable to other oxides.

\section{Experimental}

Reagents used in the study were purchased from Sigma-Aldrich unless otherwise specified and used without purification. Iron undecylenate was synthesized by the following procedure. $10.8 \mathrm{~g}(40 \mathrm{mmol})$ of $\mathrm{FeCl}_{3} \cdot 6 \mathrm{H}_{2} \mathrm{O}, 4.8 \mathrm{~g}(0.12 \mathrm{~mol})$ of $\mathrm{NaOH}$ and $22.1 \mathrm{~g}(0.12 \mathrm{~mol})$ of undecylenic acid were added to in a mixture of $80 \mathrm{ml}$ of ethanol, $60 \mathrm{ml}$ of water and $140 \mathrm{ml}$ of hexane under vigorous stirring. The mixture was heated at $70^{\circ} \mathrm{C}$ for $3 \mathrm{hrs}$ and then the organic phase was collected using a separation funnel. After washing with water for 3 times, hexane was driven off from the mixture using a rotary evaporator to obtain iron undecylenate, a waxy solid.

In a typical reaction, $2 \mathrm{ml}$ acrylonitrile (AN), $2 \mathrm{ml}$ divinylbenzene (DVB) and $1.8 \mathrm{~g}$ of iron undecylenate were mixed to form a homogeneous solution. $3 \mathrm{mg}$ of azobisisobutyronitrile (AIBN) and 100mg sodium dodecyl sulfate (SDS) were added to $25 \mathrm{ml}$ of water and the former solution introduced to the aqueous phase under sonication with a Sonics VCX500 horn $(500 \mathrm{~W}, 20 \mathrm{kHz}$, amplitude 50\%). The mixture was sonicated for 3 minutes and after a stable emulsion was formed, heated at $70^{\circ} \mathrm{C}$ for 12 hrs. Sodium chloride was added to induce aggregation of the resultant polymer-inorganic hybrid particles, which were collected by centrifugation. The 
material obtained was heated in a nitrogen atmosphere, first to $320^{\circ} \mathrm{C}$, held at this temperature for $1 \mathrm{hr}$, then to $500^{\circ} \mathrm{C}$ and held for $2 \mathrm{hrs}$ to obtain the final metal-oxide/carbon nanocomposite product.

The crystal structures of the particles were characterized using Scintag Theta-theta PAD-X X-Ray Diffractometer (Cu K a , $\lambda=1.5406 \AA$ ) and their morphologies were studied using FEI Tecnai G2 T12 Spirit Transmission Electron Microscope (120kV). Raman spectra were taken using Renishaw InVia Confocal Raman Microscope. Thermogravimetric analysis was performed using TA Instruments Q5000 IR Thermogravimetric Analyzer. Electrical conductivity measurement was made using a Lucas Signatone SP4 four-point probe station and the pellets were made using 7 tons $/ \mathrm{cm}^{2}$ of pressure. Gas adsorption analysis for porous materials was performed using a Micromeritics ASAP 2020 Accelerated Surface Area and Porosimetry System.

Electrochemical characterization of the composites as anode materials in rechargeable lithium-ion batteries was performed at room temperature in homemade Swagelok-type cells. The working electrode consisted of $80 \mathrm{wt} \%$ of the active material, $10 \mathrm{wt} \%$ of carbon black (Super-P Li from TIMCAL) as a conductivity aid, and $10 \mathrm{wt} \%$ of polymer binder (PVDF, polyvinylidene fluoride, Aldrich). Lithium foil was used as the counter and reference electrodes. A $1 \mathrm{M}$ solution of $\mathrm{LiPF}_{6}$ in a 50:50 w/w mixture of ethylene carbonate and diethyl carbonate was used as the electrolyte. Celgard 2500 polypropylene membranes are used as the separator. Assembly of cell was performed in a glove box with moisture and oxygen concentrations below $1 \mathrm{ppm}$. 
The room-temperature electrode capacities were measured using Neware CT-3008 battery testers.

\section{Results and Discussion}

Powder X-ray diffraction was performed to determine the crystalline phase of the transition metal oxide. The XRD results, shown in Figure 1(a), matches well with that of magnetite (JCPDS card no. 19-629). The broad signal in the range of 20 30 may be due to the presence of non-crystalline carbon in the composite, because the most intense reflection for graphitic carbon (002 layer) should appear at $26.8^{\circ}$. From the Scherrer's formula, the average crystallite size of the $\mathrm{Fe}_{3} \mathrm{O}_{4}$ phase is found to be $21 \mathrm{~nm}$.

Transmission Electron Micrographs (TEM) for the polymer-particle complex are shown in Figure 2(a). The material generally consists of particles with sizes in the range 200 400 nm. aggregated together. Energy Dispersive X-Ray Spectroscopy (EDX) was performed on the complex, as shown in Fig. 2(c), which confirms that iron has been successfully incorporated in the complex. The morphology of the material after calcination is shown in Figure 2(b). It consists of uniformly sized $\mathrm{Fe}_{3} \mathrm{O}_{4}$ nanoparticles embedded in a carbon matrix and the size is consistent with the average crystallite size calculated from the X-Ray diffractograms $(21 \mathrm{~nm})$. Oxidative thermal gravimetric analysis (TGA) may be used to measure the weight fraction of active material $\mathrm{Fe}_{3} \mathrm{O}_{4}$ in the composite and the data is shown in Fig. 2(d). The material is heated to $700^{\circ} \mathrm{C}$ under air so that $\mathrm{Fe}_{3} \mathrm{O}_{4}$ is oxidized to $\mathrm{Fe}_{2} \mathrm{O}_{3}$ and carbon is oxidized to $\mathrm{CO}_{2}$. From the remaining weight (of $\mathrm{Fe}_{2} \mathrm{O}_{3}$ ), the original weight fraction of $\mathrm{Fe}_{3} \mathrm{O}_{4}$ is 
calculated to be $66 \%$.

Other carboxylic acid salts of iron have been used as the precursor, for example iron oleate, but the amount of $\mathrm{Fe}_{3} \mathrm{O}_{4}$ eventually encapsulated in the product is substantially lower $(33 \%)$ than for iron undecylenate. We suspect that the higher molecular weight of oleic acid compared to undecylenic acid and the bulkier molecule of iron oleate results in less efficient incorporation in the polymer complex. In addition, the fractional weight loss of conversion of $\mathrm{Fe}(\mathrm{ole})_{3}$ to $\mathrm{Fe}_{3} \mathrm{O}_{4}(91 \%)$ is larger than conversion of $\mathrm{Fe}(\text { ole })_{3}$ to $\mathrm{Fe}_{3} \mathrm{O}_{4}(87 \%)$, because of the larger molecular weight of $\mathrm{Fe}(\mathrm{ole})_{3}$. Iron (III) acetylacetonate $\left(\mathrm{Fe}(\mathrm{acac})_{3}\right)$, which has a lower molecular weight than $\mathrm{Fe}(\text { undec })_{3}$ was also investigated. In this case, the higher water solubility of the particle precursor does not allow formation of stable micelles required for emulsion polymerization.

Polyacrylonitrile is frequently used to synthesize graphitic materials through calcination at high temperatures. To obtain highly graphitic carbon, PAN should be subjected to three consecutive processes, namely, stabilization, carbonization and graphitization. ${ }^{26}$ In the stabilization step, PAN is heated to $200 \sim 300^{\circ} \mathrm{C}$ in air and converted to a cyclic or a ladder compound, followed by treatment in nitrogen atmosphere to about $1000^{\circ} \mathrm{C}$ to achieve carbonization of the material. The third step, know as graphitization, is to heat the material to $1500 \sim 3000^{\circ} \mathrm{C}$ under argon atmosphere to improve the ordering and orientation of the crystallites. Because the present system contains metal oxides, if the material is heated to temperatures above $\sim 700^{\circ} \mathrm{C}$ for the sake of increasing the graphite content in the product, there is the 
possibility of carbon reducing the metal oxide to pure metal. As a compromise, we use a carbonization protocol requiring heating the material at $500{ }^{\circ} \mathrm{C}$ in dry $N_{2}$.

The Raman spectrum of the $\mathrm{Fe}_{3} \mathrm{O}_{4}-\mathrm{C}$ composite are shown in Figure 3. It is immediately noticeable that the spectrum contains two prominent peaks at around 1350 and 1590 wavenumbers. Raman spectra for carbon materials usually contain several peaks. In particular, the spectrum can be deconvoluted to five bands, corresponding to ideal graphite (G $\left.1580 \mathrm{~cm}^{-1}\right)$, a disordered graphitic lattice (D1 1350 $\mathrm{cm}^{-1}$, D2 $1620 \mathrm{~cm}^{-1}$ and D4 $1200 \mathrm{~cm}^{-1}$ ), or amorphous carbon (D3 $\left.1500 \mathrm{~cm}^{-1}\right)^{27,28}$. G and D2 both come from $\mathrm{sp}^{2}$ carbon vibrations, which can be difficult to distinguish, and in some works have been treated as one single component in the fitting procedure $^{28,29}$. Lorentzian functions were used in the fitting and the calculated positions for the peaks are: G $1596 \mathrm{~cm}^{-1}$, D1 $1349 \mathrm{~cm}^{-1}$, D3 $1471 \mathrm{~cm}^{-1}$, D4 $1230 \mathrm{~cm}^{-1}$. This analysis indicates the carbon in the composite we obtained is partially graphitic.

Conductivity measurements performed using the four-point probe technique were used to further evaluate the properties of carbon derived from pyrolysis of PAN-DVB. These measurements show that the conductivity of carbon obtained from pyrolysis of PAN-DVB at $500^{\circ} \mathrm{C}$ is $2 \times 10^{-4} \mathrm{~S} / \mathrm{cm}$. In comparison, carbon prepared from pyrolysis of PAN-DVB at $900^{\circ} \mathrm{C}$ for $5 \mathrm{hrs}$ yields conductivities that are more than six orders of higher, $\sigma \approx 3 \times 10^{2} \mathrm{~S} / \mathrm{cm}$.

Magnetite has the formula $\mathrm{Fe}^{2+}\left[\mathrm{Fe}^{3+}{ }_{2}\right] \mathrm{O}_{4}$ and adopts an inverse spinel structure. In each unit cell (containing 8 multiples of $\mathrm{Fe}_{3} \mathrm{O}_{4}$ ), 8 out of $16 \mathrm{Fe}^{3+}$ ions occupy 8 out of the 64 tetrahedral sites and all the $\mathrm{Fe}^{2+}$ ions and the remaining $8 \mathrm{Fe}^{3+}$ ions are 
distributed in 16 out of 32 octahedral sites. An early work has studied the use of $\mathrm{Fe}_{3} \mathrm{O}_{4}$ as electrode materials in LIBs and based on XRD data and measured potentials vs. $\mathrm{Li}^{+} / \mathrm{Li}$ for different lithiated iron oxides, Thackeray et al. ${ }^{30}$ proposed that the lithiation of $\mathrm{Fe}_{3} \mathrm{O}_{4}$ follows the following pathway:

$$
\begin{gathered}
\left(\mathrm{Fe}^{3+}\right)\left[\mathrm{Fe}_{2}^{3+/ 2+}\right] \mathrm{O}_{4} \stackrel{1.0 \mathrm{Li}}{\longrightarrow}\left[\mathrm{Li}^{+} \mathrm{Fe}^{3+/ 2+}\right]\left[\mathrm{Fe}_{2}^{3+/ 2+}\right] \mathrm{O}_{4} \text { (Phase 1) } \\
\stackrel{1.0 L i}{\longrightarrow}\left(\mathrm{Li}^{+}\right)\left[\mathrm{Li}^{+} \mathrm{Fe}^{2+}\right]\left[\mathrm{Fe}_{2}^{2+}\right] \mathrm{O}_{4} \text { (Phase 2) } \\
\stackrel{6.0 \mathrm{Li}}{\longrightarrow} 4 \mathrm{Li}_{2} \mathrm{O}+3 \mathrm{Fe} \text { (Phase 3) }
\end{gathered}
$$

Here parentheses denote ions in tetrahedral sites and square brackets denote ions in octahedral sites. During the insertion of up to $1.0 \mathrm{Li}$, the $\mathrm{Li}^{+}$ions fill up octahedral vacancies, with $\mathrm{Fe}^{3+}$ in the tetrahedral sites displaced to octahedral sites, leading to the formation of a rock-salt-like structure of $\mathrm{Li}_{1.0} \mathrm{Fe}_{3} \mathrm{O}_{4}$ at the end of this step. Further insertion of lithium involves the filling of the tetrahedral sites by $\mathrm{Li}^{+}$ions. Metallic iron is extruded from the rock-salt structure to accommodate the incoming $\mathrm{Li}^{+}$ions.

Cyclic voltammograms for $\mathrm{Fe}_{3} \mathrm{O}_{4}-\mathrm{C}$ composites are shown in Figure 4 (a) (scan rate $=0.2 \mathrm{mV} / \mathrm{s}$ ). The patterns are consistent with the $\mathrm{CV}$ results from other reports on $\mathrm{Fe}_{3} \mathrm{O}_{4}-\mathrm{C}$ composites ${ }^{18,31}$. In the anodic process, starting from the second cycle, the lithium intercalation occurs mainly at around $0.7 \mathrm{~V}$ and in the cathodic process the oxidation of $\mathrm{Fe}^{0}$ occurs at around $1.8 \mathrm{~V}^{30}$. In the first cycle, the intercalation occurred at a lower voltage of around $0.4 \mathrm{~V}$, probably because of an overpotential arising from the crystal structure change from inverse spinel structure to rock salt type structure ${ }^{30}$. The voltage-capacity profiles for the complex cycled at different charging rates $(1 \mathrm{C}$ or 
0.5 C) are shown Figure 4 (b). The lithium intercalation plateaus are not as flat for the $\mathrm{Fe}_{3} \mathrm{O}_{4}$ in carbon composites compared to the pure oxide ${ }^{18,31}$, probably because of reduction in crystallinity during the process of the carbon formation for the composite $^{10,32}$.

Cycling performance data for the $\mathrm{Fe}_{3} \mathrm{O}_{4}-\mathrm{C}$ composite are shown in Figure 5. The material was cycled at $1 \mathrm{C}$ and $0.2 \mathrm{C}$, respectively for 100 cycles and the performance under different charging rates ranging from $0.5 \mathrm{C}$ to $5 \mathrm{C}$ was also studied. The capacities are calculated based on the metal oxide mass because the capacity-voltage profiles do not indicate significant contribution from lithium intercalation into the carbon host. It is apparent from the figure that the composites show very stable performance and little fading for 100 cycles, even at $1 \mathrm{C}$ charging rate. The performance is also stable for higher charging rates (20 cycles are shown as examples). The performance of bare $\mathrm{Fe}_{3} \mathrm{O}_{4}$ nanoparticles (50nm in size, commercially available from Alfa Aesar) as the anode material is also shown in Fig. 5(d) for comparison purposes; the clear improvements provided by the composite materials is visible from this plot. The performance of pure carbon made from pyrolysis of PAN-DVB is also shown. It is seen that this material does not make any significant contribution to the lithium storage capacity.

The stable electrochemical performance of the $\mathrm{Fe}_{3} \mathrm{O}_{4}-\mathrm{C}$ nanocomposites can be attributed to different features of the materials. Considering the relatively low electronic conductivity of the carbon component, it is not a consequence of enhanced electronic transport afforded by the carbon. The uniformly sized $\mathrm{Fe}_{3} \mathrm{O}_{4}$ nanoparticles 
are embedded in the carbon matrix, which might serve to alleviate the volume change incurred during the repeated cycling. A porous, mechanically flexible reinforcement that allows good penetration by the electrolyte into the active material is therefore considered advantageous. The pore size distribution data shows that most of the pores are less than $10 \mathrm{~nm}$ in size. Nitrogen adsorption analysis was performed on the composite and the surface area measured by the BET method is $122 \mathrm{~m}^{2} / \mathrm{g}$, with the isotherms and the pore size distribution for the composite shown in Fig. 6. The BET surface area of pure carbon obtained from pyrolysis of the PAN-DVB polymer (without $\mathrm{Fe}_{3} \mathrm{O}_{4}$ nanoparticles) is about three times higher, $369 \mathrm{~m}^{2} / \mathrm{g}$.

The size of the $\mathrm{Fe}_{3} \mathrm{O}_{4}$ nanoparticles also seems to be an important factor in determining the electrochemical performance. Average diameters of $\mathrm{Fe}_{3} \mathrm{O}_{4}$ particles synthesized using hydrothermal/solvothermal methods are usually greater than $150 \mathrm{~nm}$ because the particles are typically aggregates of smaller primary crystallites. In the current method, the size of the $\mathrm{Fe}_{3} \mathrm{O}_{4}$ nanoparticles is relatively small and the greater surface area and shorter diffusion length may allow easier access of the active material by the lithium ions.

The method developed for creating $\mathrm{Fe}_{3} \mathrm{O}_{4}-\mathrm{C}$ composites can be applied to synthesize nanocomposites of various other metal oxides (or other related materials such as pure metal) embedded in carbon matrices. Another interesting material is $\mathrm{MnO}$, which has a theoretical lithium storage capacity of $755 \mathrm{mAh} / \mathrm{g}$. MnO undergoes conversion reaction in lithium-ion batteries: $2 \mathrm{Li}+\mathrm{MnO} \rightarrow \mathrm{Mn}+\mathrm{Li}_{2} \mathrm{O}^{33,34}$ and upon lithium insertion, $\mathrm{Mn}$ grains $<5 \mathrm{~nm}$ in size are formed. $\mathrm{MnO}-\mathrm{C}$ composites can be 
synthesized using manganese (II) undecylenate as the precursor. Figure 7(a) shows the X-ray diffractogram for the MnO-C composite, which matches well with $\mathrm{MnO}$ (JCPDS card no. 07-230). Again a broad band is observed in the range of 20-30, but no sharp peak could be found at $26.8^{\circ}$, indicating that the carbon component is largely amorphous. TGA is used to determine the fraction of $\mathrm{MnO}$ in the composite. Upon heating to $700^{\circ} \mathrm{C}$ in air, $\mathrm{MnO}$ is oxidized to $\mathrm{Mn}_{2} \mathrm{O}_{3}$ and the weight fraction of $\mathrm{MnO}$ in the composite is calculated to be $58 \%$ assuming all the remaining material is carbon. The morphology of the MnO-C composite is shown in Figure 7(b) and similar to the case of $\mathrm{Fe}_{3} \mathrm{O}_{4}, \mathrm{MnO}$ nanoparticles embedded in a carbon matrix are obtained.

A typical cyclic voltammogram for the MnO-C composite is shown in Figure 8(a) and lithium insertion $/ \mathrm{Mn}^{2+}$ reduction seems to occur at around $0.5 \mathrm{~V}$ against $\mathrm{Li} / \mathrm{Li}^{+}$, which is consistent with previous reports on $\mathrm{MnO}$ anode materials ${ }^{35}$. Voltage-capacity curves at $0.5 \mathrm{C}$ and $1 \mathrm{C}$ charging rates are shown in Figure $8(\mathrm{~b})$ and cycling data for the composite run at $1 \mathrm{C}, 0.2 \mathrm{C}$ and at varied charging rates are shown in Figure $8(\mathrm{c})$. Similar to what was observed for the $\mathrm{Fe}_{3} \mathrm{O}_{4}-\mathrm{C}$ composite, little capacity fade is observed even when the material is subject to $1 \mathrm{C}$ charging rate for over $>100$ cycles. Cycling at higher charging rates is also seen to give stable performance. The slight increase in capacity has been reported before in the literature and possible reasons include formation of higher oxidation state products and/or electrochemical grinding effect. ${ }^{36}$ When comparing the capacity here with that in the literature (e.g. refs. 33 and 34 ), the charging rates used need to be taken into account. Ref. 34 uses $100 \mathrm{mAh} / \mathrm{g}$, while ref. 33 reports results based on different rates but only shows $<5$ cycles (the 
result over 150 cycles appears to be run with $50 \mathrm{~mA} / \mathrm{g}$ ). Therefore a prominent feature of the current protocol is the ability to yield materials with stable performance at moderately high charging rates.

\section{Conclusion}

In conclusion, a one-step free-radical polymerization method is used to synthesize cross-linked metal-oxide/poly(acrylonitrile) nanocomposites. Pyrolysis of the composite at moderate temperatures in an inert atmosphere yields metal-oxide/carbon particles comprised of uniformly distributed metal oxide nanoparticles in a partially graphitic, but poorly conducting carbon host. The versatility of the approach has been demonstrated using two different metal oxides, $\mathrm{Fe}_{3} \mathrm{O}_{4}$ and $\mathrm{MnO}$. When evaluated as anode materials in lithium ion batteries, composites of both materials display stable performance at low and high current densities.

\section{Acknowledgements}

This material is based on work supported as part of the Energy Materials Center at Cornell, an Energy Frontier Research Center funded by the U.S. Department of Energy, Office of Basic Energy Sciences under Award Number DE-SC0001086. JS acknowledges support from Award No. KUS-C1-018-02 made by King Abdullah University of Science and Technology (KAUST). Facilities available through the KAUST-Cornell Center of energy and sustainability (Award No. KUS-C1-018-02) and by the Cornell Center for Materials Research (CCMR; Award No. DMR-0079992) were used for the study. 


\section{References}

J. M. Tarascon and M. Armand, Nature, 2001, 414, 359.

J. Cabana, L. Monconduit, D. Larcher, and M. R. Palacin, Advanced Materials, 2010, 22, E170.

M. S. Park, G. X. Wang, Y. M. Kang, D. Wexler, S. X. Dou, and H. K. Liu, ANGEWANDTE CHEMIE-INTERNATIONAL EDITION, 2007, 46, 750.

Z. Y. Yuan, F. Huang, C. Q. Feng, J. T. Sun, and Y. H. Zhou, MATERIALS CHEMISTRY AND PHYSICS, 2003, 79, 1.

Y. K. Zhou, L. Cao, F. B. Zhang, B. L. He, and H. L. Li, Journal of the Electrochemical Society, 2003, 150, A1246.

D. Larcher, G. Sudant, J. B. Leriche, Y. Chabre, and J. M. Tarascon, J. Electrochem. Soc., 2002, 149, A234.

X. W. Lou, L. A. Archer, and Z. C. Yang, Advanced Materials, 2008, 20, 3987.

X. W. Lou, Y. Wang, C. Yuan, J. Y. Lee, and L. A. Archer, ADVANCED MATERIALS, 2006, 18, 2325.

X. W. Lou, D. Deng, J. Y. Lee, J. Feng, and L. A. Archer, Advanced Materials, 2008, 20, 258.

W. M. Zhang, X. L. Wu, J. S. Hu, Y. G. Guo, and L. J. Wan, Advanced Functional Materials, 2008, 18, 3941.

T. Yuan, X. Yu, R. Cai, Y. K. Zhou, and Z. P. Shao, Journal of Power Sources, 195, 4997.

T. H. Yang, Y. L. Guo, X. C. Zhou, and Y. M. Liu, Journal of Inorganic Materials, 2009, 24, 147.

X. W. Lou, D. Deng, J. Y. Lee, and L. A. Archer, Chemistry of Materials, 2008, 20, 6562.

X. W. Lou, C. M. Li, and L. A. Archer, Advanced Materials, 2009, 21, 2536.

J. S. Chen, Y. L. Cheah, Y. T. Chen, N. Jayaprakash, S. Madhavi, Y. H. Yang, and X. W. Lou, Journal of Physical Chemistry C, 2009, 113, 20504.

T. Muraliganth, A. V. Murugan, and A. Manthiram, Chemical Communications, 2009, 7360.

S. L. Jin, H. G. Deng, D. H. Long, X. J. Liu, L. A. Zhan, X. Y. Liang, W. M. Qiao, and L. C. Ling, Journal of Power Sources, 2011, 196, 3887.

M. Zhang, D. N. Lei, X. M. Yin, L. B. Chen, Q. H. Li, Y. G. Wang, and T. H. Wang, Journal of Materials Chemistry, 2010, 20, 5538.

S. Q. Chen and Y. Wang, Journal of Materials Chemistry, 2010, 20, 9735.

Y. Liu, J. Y. Xie, Y. Takeda, and J. Yang, Journal of Applied Electrochemistry, 2002, 32, 687.

I. S. Kim, G. E. Blomgren, and P. N. Kumta, Electrochemical and Solid State Letters, 2004, 7, A44.

J. Read, D. Foster, J. Wolfenstine, and W. Behl, Journal of Power Sources, 2001, 96, 277.

L. Balan, R. Schneider, P. Willmann, and D. Billaud, Journal of Power Sources, 2006, 161, 587.

M. Egashira, H. Takatsuji, S. Okada, and J. Yamaki, Journal of Power Sources, 2002, 107, 56.

G. Derrien, J. Hassoun, S. Panero, and B. Scrosati, Advanced Materials, 2007, 19, 2336.

M. S. A. Rahaman, A. F. Ismail, and A. Mustafa, Polymer Degradation and Stability, 2007, 92, 1421.

A. Sadezky, H. Muckenhuber, H. Grothe, R. Niessner, and U. Poschl, Carbon, 2005, 43, 
1731.

F. Bonhomme, J. C. Lassegues, and L. Servant, Journal of the Electrochemical Society, 2001, 148, E450.

B. Dippel, H. Jander, and J. Heintzenberg, Physical Chemistry Chemical Physics, 1999, 1, 4707.

M. M. Thackeray, Journal of the American Ceramic Society, 1999, 82, 3347.

H. Liu, G. X. Wang, J. Z. Wang, and D. Wexler, Electrochemistry Communications, 2008, 10, 1879.

S. A. Needham, G. X. Wang, K. Konstantinov, Y. Tournayre, Z. Lao, and H. K. Liu, Electrochem. Solid State Lett., 2006, 9, A315.

K. F. Zhong, X. Xia, B. Zhang, H. Li, Z. X. Wang, and L. Q. Chen, Journal of Power Sources, 2010, 195, 3300.

34 J. Liu and Q. M. Pan, Electrochemical and Solid State Letters, 2010, 13, A139.

35 X. Q. Yu, Y. He, J. P. Sun, K. Tang, H. Li, L. Q. Chen, and X. J. Huang, Electrochemistry Communications, 2009, 11, 791.

36 J. S. Do and C. H. Weng, Journal of Power Sources, 2005, 146, 482. 


\section{Figures}

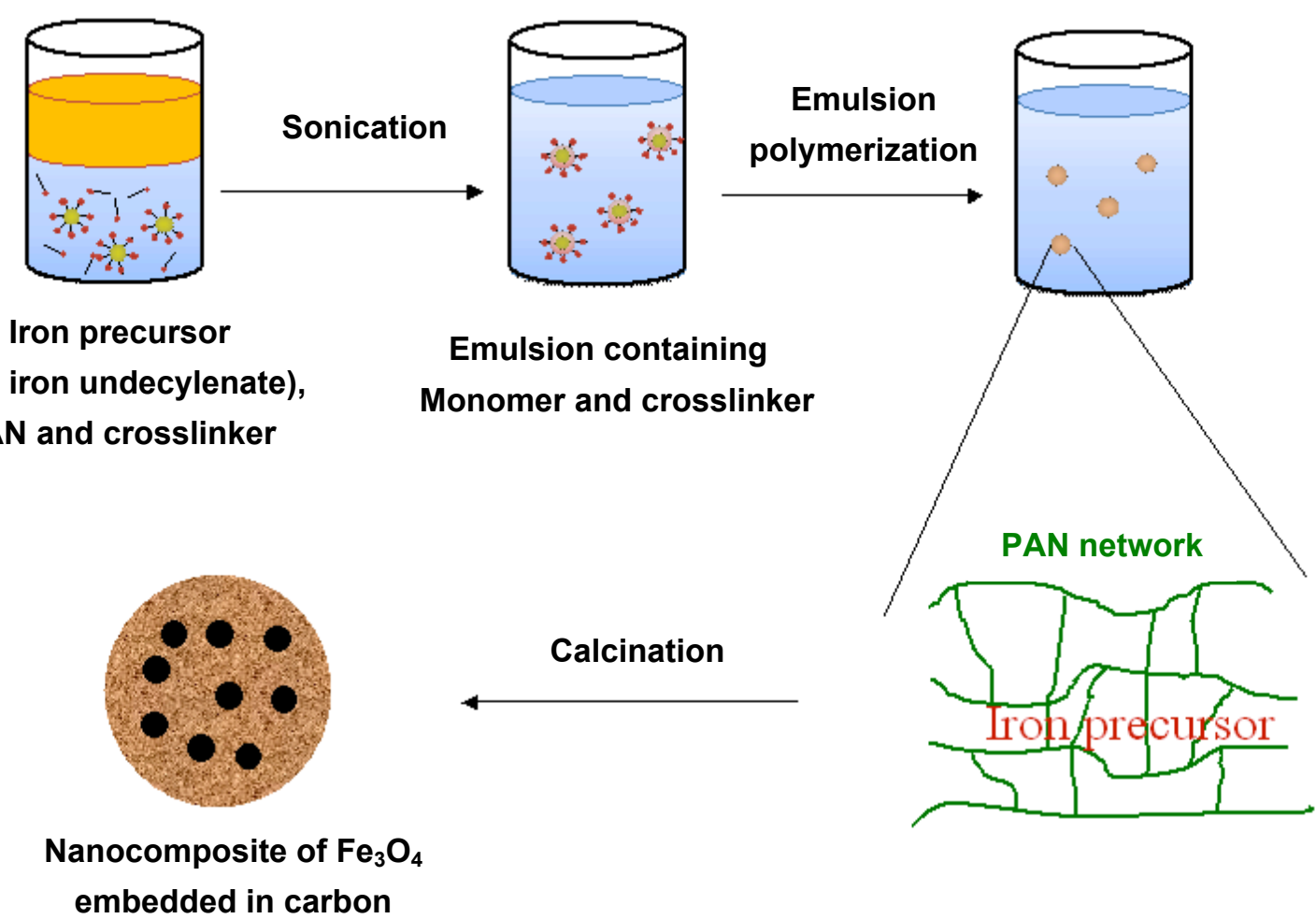

Scheme 1: In situ synthesis scheme for $\mathrm{Fe}_{3} \mathrm{O}_{4}-\mathrm{C}$ nanocomposite

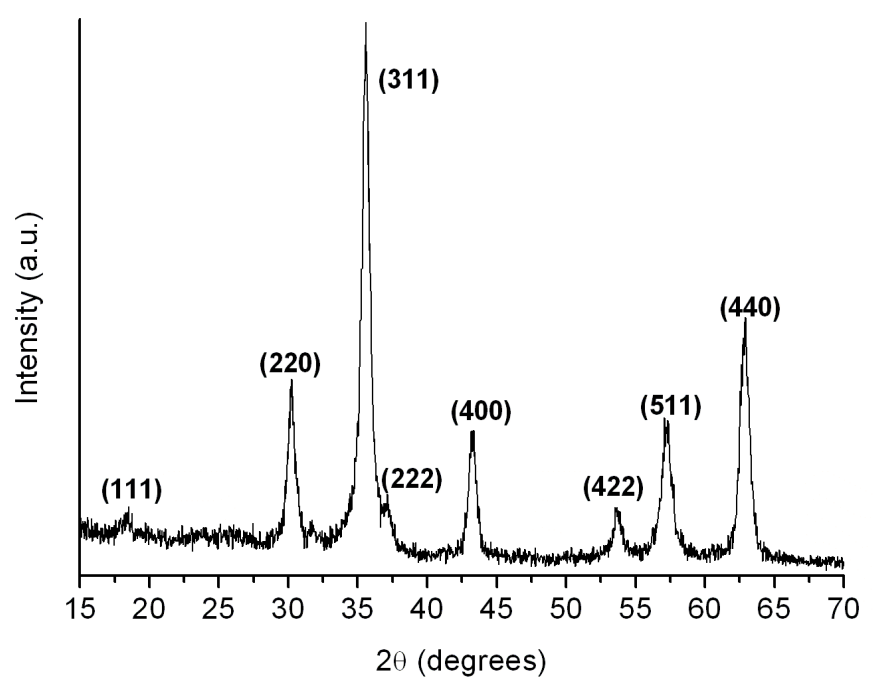

Fig. 1 XRD pattern for the $\mathrm{Fe}_{3} \mathrm{O}_{4}-\mathrm{C}$ composite created by pyrolysing the as-prepared PAN-Fe(undec) $)_{3}$ complex. 

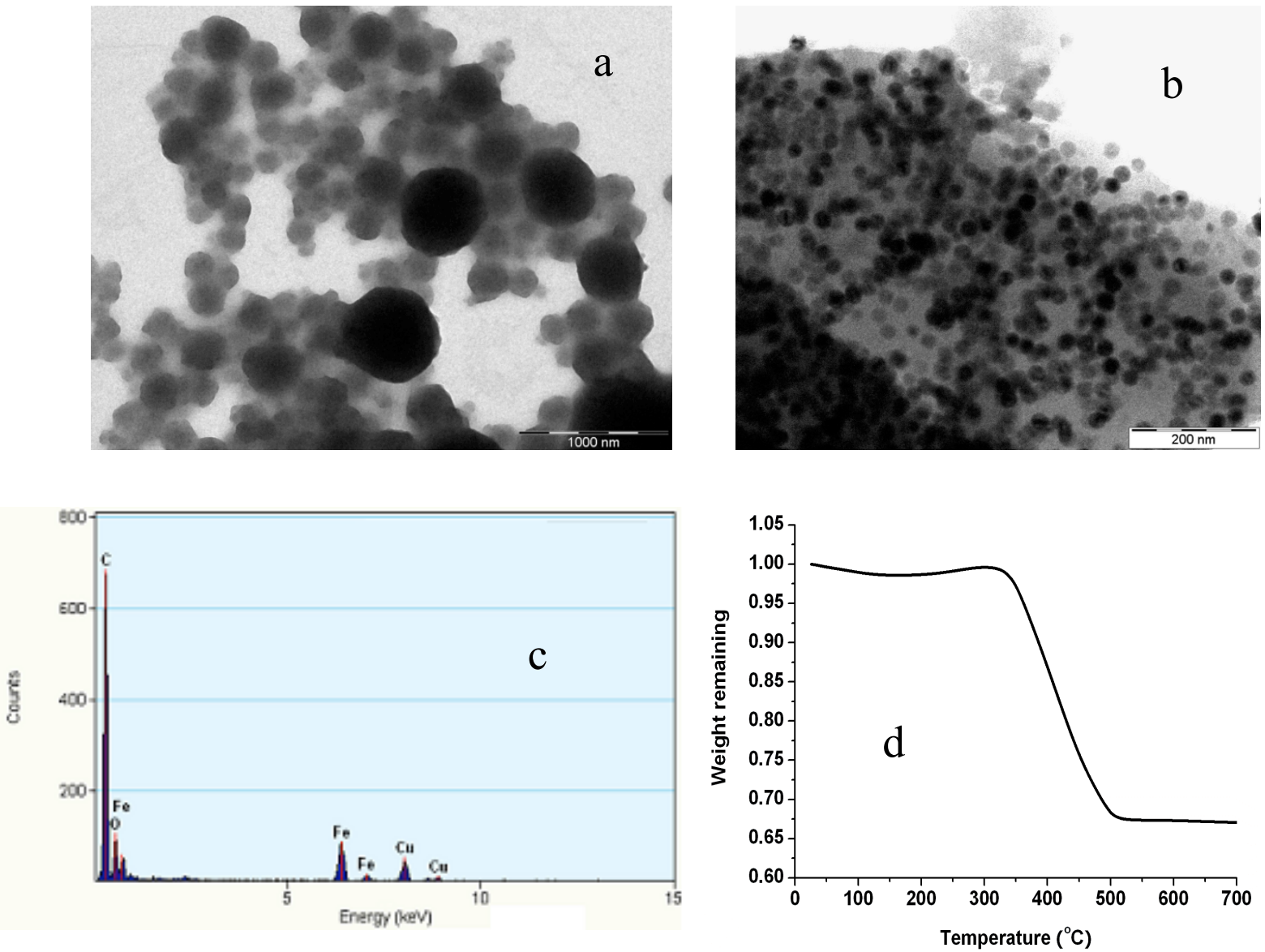

Fig. 2 (a) Morphology of polymer-iron complex; (b) Morphology of $\mathrm{Fe}_{3} \mathrm{O}_{4}-\mathrm{C}$ composite; (c) EDS spectrum for the polymer-iron complex; (d) TGA data for the $\mathrm{Fe}_{3} \mathrm{O}_{4}-\mathrm{C}$ composite

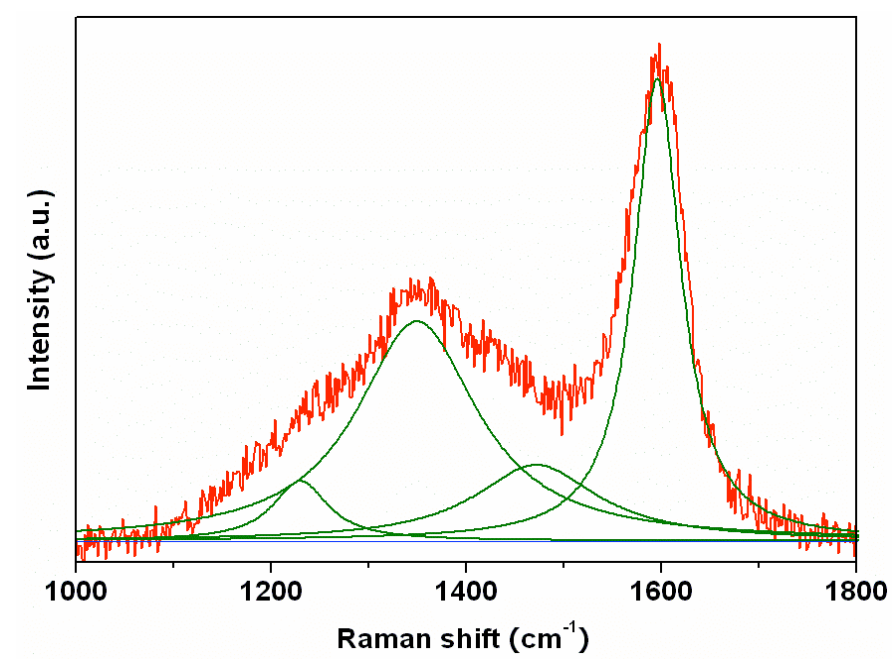

Fig. 3 Raman spectrum for the $\mathrm{Fe}_{3} \mathrm{O}_{4}-\mathrm{C}$ composite, deconvoluted into peaks for graphitic carbon, disordered graphite lattices and amorphous carbon 

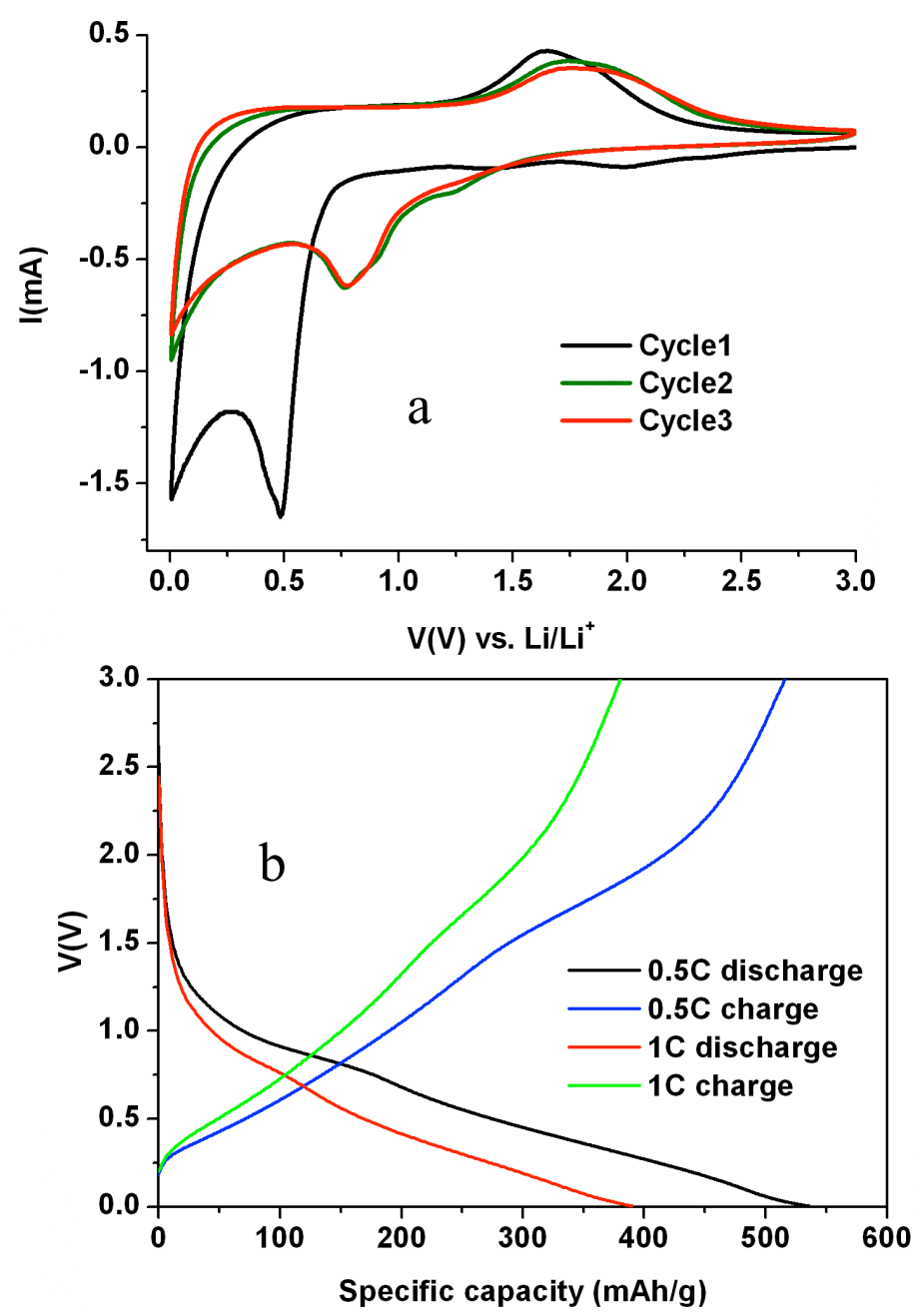

Fig. 4 Cyclic Voltammograms and voltage-capacity profiles for $\mathrm{Fe}_{3} \mathrm{O}_{4}-\mathrm{C}$ nanocomposites.

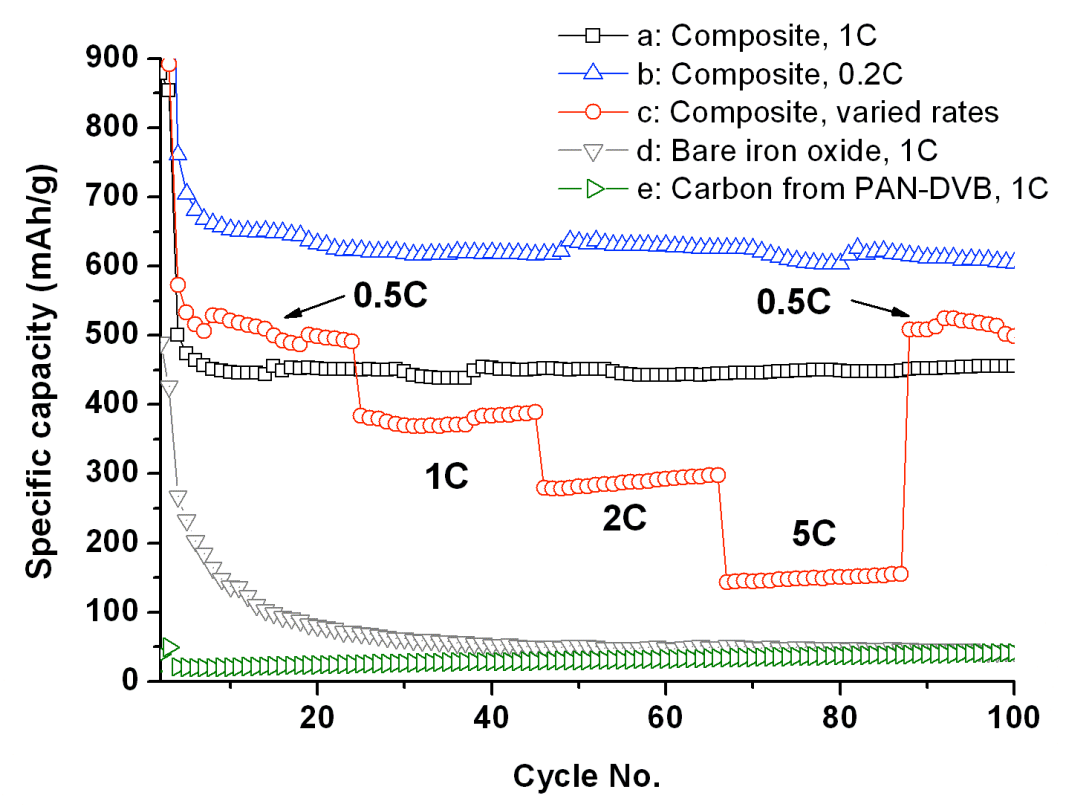


Fig. 5 Cycling performance for (a) $\mathrm{Fe}_{3} \mathrm{O}_{4}-\mathrm{C}$ composites run at $1 \mathrm{C}(924 \mathrm{mAh} / \mathrm{g})$; (b) composite run at $0.2 \mathrm{C}$; (c) composite run at charging rates; (d) bare $\mathrm{Fe}_{3} \mathrm{O}_{4}$ nanoparticles run at 1C; (e) bare carbon made from pyrolysis of PAN-DVB run at $1 \mathrm{C}$.
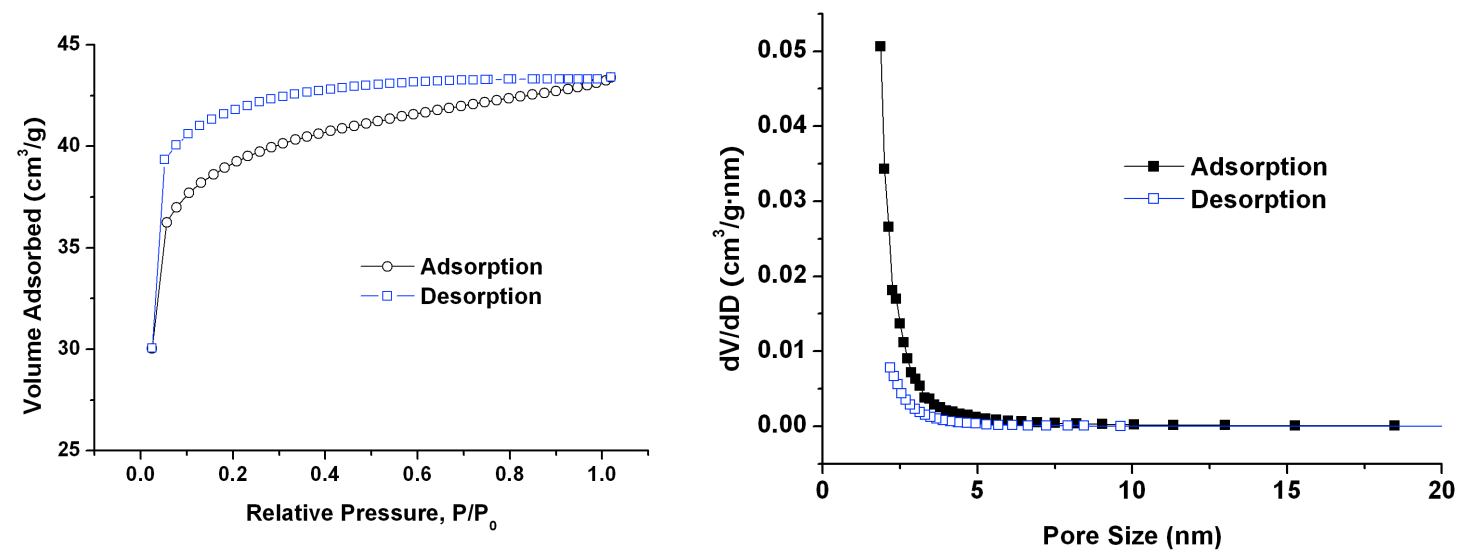

Fig. 6 Nitrogen adsorption isotherms and pore size distribution for the $\mathrm{Fe}_{3} \mathrm{O}_{4}-\mathrm{C}$ composite.

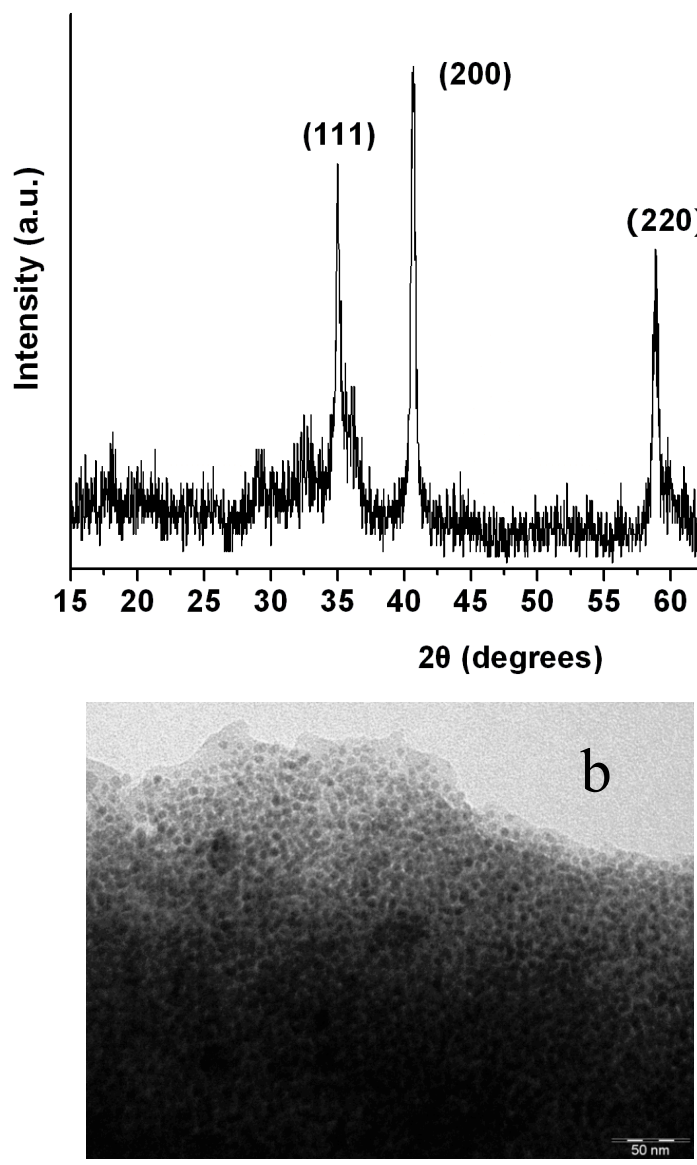

Fig. 7 (a) X-Ray diffractogram (b) TEM image for MnO-C composite 

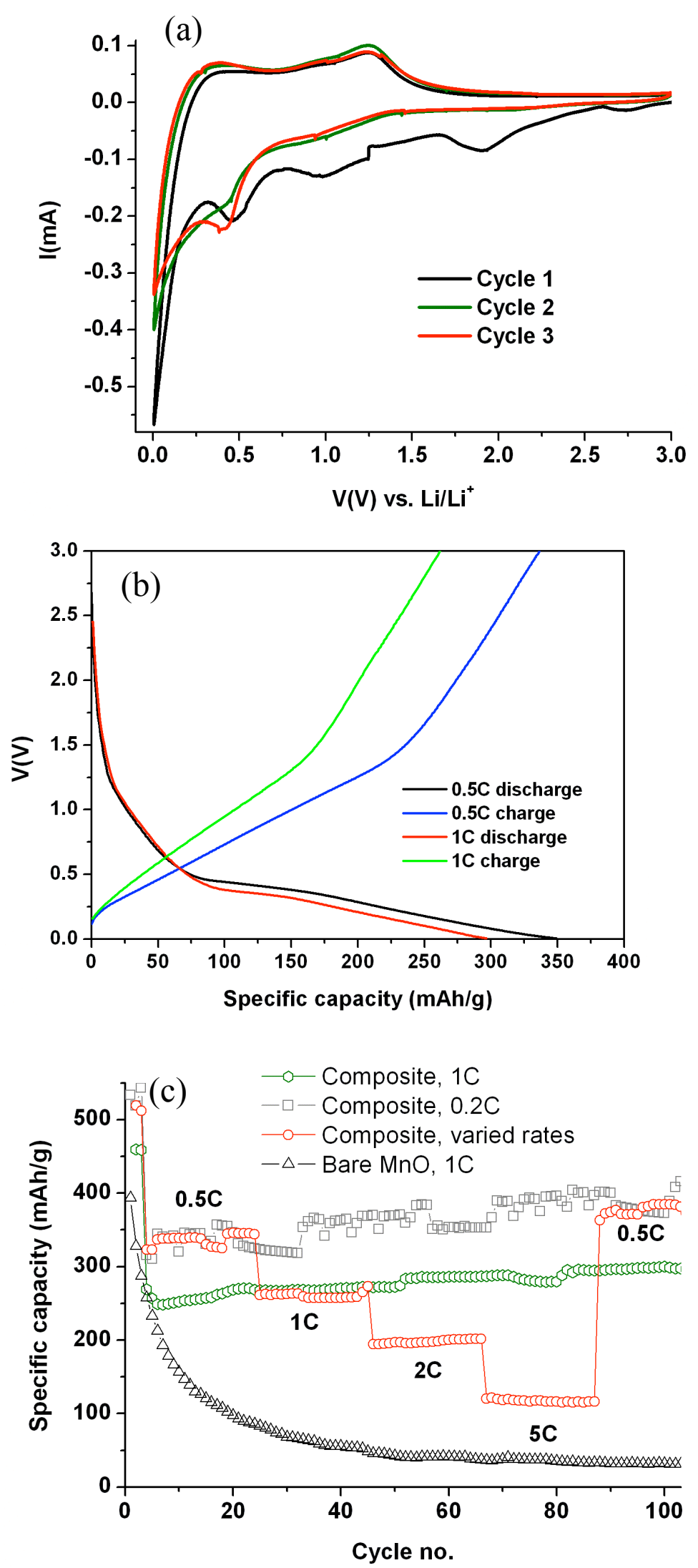

Fig. 8 (a) Cyclic voltammograms (b) voltage-capacity profiles of MnO-C composite; (c) cycling performance of $\mathrm{MnO}-\mathrm{C}$ composite at $1 \mathrm{C}(755 \mathrm{mAh} / \mathrm{g}), 0.2 \mathrm{C}$ and at varied charging rates, and cycling performance of pure $\mathrm{MnO}$. 